\title{
A Coupled Electro-Chemo-Mechanical Model for Li-ion Batteries: Effect of Stress on the Voltage Hysteresis of Lithium Ion Batteries
}

\author{
Pengfei Yu ${ }^{1,2}$, Junwen Xiao ${ }^{1}$, Hai Hu${ }^{1}$, Mingju Lin ${ }^{1}$, and Yaohong Suo ${ }^{1, *}$ \\ ${ }^{1}$ School of Mechanical Engineering and Automation, Fuzhou University, Fuzhou, 350108, China \\ ${ }^{2}$ State Key Laboratory for Strength and Vibration of Mechanical Structures, School of Aerospace, \\ Xi' an Jiaotong University, Xi' an 710049, People Republic of China \\ *E-mail: yaohongsuo@126.com
}

Received: 2 July 2021 / Accepted: 9 August 2021 / Published: 10 September 20211

\begin{abstract}
Experiments have shown that stress has a significant effect on the hysteresis loop of the electrode potential while charging or discharging Li-ion batteries. In this work, considering the influence of stress on lithium-ion diffusion and electrode potential, a fully coupled electro-chemo-mechanical model is developed in a spherical electrode particle under galvanostatic operation. Then, some simulations are carried out to investigate the distribution of lithium-ion concentration, diffusion-induced stresses and electric potential. Meanwhile, the influences of C-rate and electrode particle radius are also discussed. Numerical results show that the smaller C-rate and electrode particle radius are beneficial in reducing the diffusion-induced stresses and improving the effective capacity of Li-ion batteries. Finally, some comparisons of lithium-ions concentration and the hysteresis of electrode potential between the present model and Jin's model (without the effect of deformation on diffusion) are performed. The work can provide some tips for designing electrodes in Li-ion batteries with a high capacity and durability.
\end{abstract}

Keywords: Voltage hysteresis; Diffusion-induced stress; Electro-chemo-mechanical model; Lithiumion batteries

\section{$\underline{\text { FULL TEXT }}$}

(C) 2021 The Authors. Published by ESG (www.electrochemsci.org). This article is an open access article distributed under the terms and conditions of the Creative Commons Attribution license (http://creativecommons.org/licenses/by/4.0/). 